\title{
SALAR TÜRKÇESİ VE TÜRKIYYE TÜRKÇESİ ARASINDAKİ YALANCI EŞDEĞER SÖZCÜKLER
}

\section{Mehmet ÖZEREN*}

\section{Özet}

Oğuz grubu Türk lehçeleri içerisinde yer alan Salar Türkçesi, Çin'in Çinghai bölgesindeki Hunhua (Salır) çevresinde, Şincian Uygur özerk bölgesinin Gulca şehrinde, Gansu eyaletinde, Lan'çjou ve Pekin'de yaşayan Salar Türkleri tarafindan konuşulmaktadır. Salar Türkleri bu bölgelerde Çin, Dungan ve Tibetlilerle iç içe yaşamaktadırlar. Dolayısıyla uzun yıllar bu halklar ile sıkı bir temas içerisinde olmuşlardır. Salar Türkleri günlük hayatta birkaç dil bilseler de kendi aralarında ve aile içerisinde Salar Türkçesini, resmi işlemlerde ise Çinceyi kullanmaktadırlar.

Konuşuldukları coğrafya açısından birbirinden oldukça uzak durumda bulunan Salar Türkçesi ile Türkiye Türkçesi yazı dili arasında anlamca örtüşmeyen ancak aynı yapıya sahip sözcükler bulunmaktadır. Bu sözcükler eşdeğer gibi görünmelerine rağmen anlamca farklılık arz ettiklerinden yalancı eşdeğer olarak adlandırılmaktadırlar. Yalancı eşdeğer sözcükler, tam veya yarı yalancı eşdeğer olabilmektedir. Yarı yalancı eşdeğer sözcükler arasında bazı anlamların örtüştüğü bazı anlamların ise örtüşmediği görülür:

ton "elbise" (SSY - 514) - don "giysi; vücudun belden aşağısına giyilen uzun veya kısa iç giysisi, külot” (TT)

uy "ev; y1lan yuvası" (SSY - 532) - ev "bir kimsenin veya ailenin içinde yaşadiğ yer, konut, hane" (TT)

Tam yalancı eşdeğer sözcükler arasında ise anlam açısından hiçbir örtüşme bulunmaz:

üçince "mart" (SSY - 538) - üçüncü "üç rakamının sırasını anlatır" (TT)

yohblan- yohlan- "fakirleş-" (SSY - 363) - yokla-n- "yoklama işine konu ol-; yokla-: dokunarak incele-; bak-, gözden geçir-, kontrol et-" (TT)

Bu çalışmada Oğuz grubu lehçeleri olan Salar Türkçesinden Türkiye Türkçesine aktarma yaparken iki lehçe arasında karşılaşılabilecek güçlüklerden biri olan yalancı eş sözcükler, tespit edilerek önce sözcük türlerine göre daha sonra yarı ve tam yalancı eşdeğerler olarak siniflandırılacaktır.

Anahtar Sözcükler: Salar Türkçesi, Türkiye Türkçesi, Yalancı Eşdeğer.

\section{FALSE EQUIVALENCE WORDS BETWEEN SALAR TURKISH AND TURKEY TURKISH}

\begin{abstract}
Salar Turkish in Turkish dialects of Ghuzz group is spoken by Salar Turks living in Cinghai region of China, around Hunhua (Salır), in Gulca city of Sincian Uighur autonomous region, in Gansu province, in Lan'çjou and Pekin. Salar Turks live together wtih China, Dungan, and Tibetans in these regions. Therefore, they have been in a close contact with these peoples for long years, Although Salar Turks know several languages in daily life, they
\end{abstract}

\footnotetext{
* Öğr. Gör. Dr.; Ardahan Üniversitesi, İnsani Bilimler ve Edebiyat Fakültesi, Türk Dili ve Edebiyatı Bölümü, mehmetozeren@hotmail.com.
} 
use Salar Turkish among themselves and their family and they use Chinese in official transactions.

There are semantic nonoverlapping words having the same structure between written languages of Salar and Turkey Turkish that are quite distant from each other in terms of geography in which they are spoken. Although these words look like equivalence, they are called false equivalance because of their semantic diversity. False equivalence words may be full or half false equivalence. It is seen some semantic overlapping and nonoverlapping words among half false equivalence words:

ton "dress" (SSY - 514) - don "clothes; long or short underclothes worn for the lower part of the body, panties" (TT)

uy "home; snake's nest" (SSY - 532) - ev "a place where a person or family live, house, household" (TT)

There is not semantic overlapping in full false equivalence words. (TT)

üçince "march" (SSY - 538) - üçüncü " tells the order of number three "

yohlan- yohlan- "get poor" (SSY - 363) - yokla-n- " subject to inspection; yokla- review by touch, review, check" (TT)

In this study, false equivalence words one of the difficulties encountered between two dialects while transferring from Salar Turkish to Turkey Turkish which are from Ghuzz group dialects will be identified and classified firstly according to the parts of speech and then will be classified as full and half false equivalances.

Keywords: Salar Turkish, Turkey Turkish, False Equivalance.

\section{Giriş}

\section{1. Salar Türkçesi ${ }^{1}$}

Salar Türkçesi, 13. yüzyılda Moğol istilası nedeniyle Semerkant bölgesinden bugünkü Çin Halk Cumhuriyetinin kuzeydoğu bölgesine göç etmiş olan Oğuz boyuna mensup Salar Türkleri tarafından konuşulan, henüz yazı dili hâline gelmemiş bir Türk lehçesidir. Salar Türkçesinin konuşur sayısı 142.000 olarak verilmekteyse de $^{2}$ genel olarak günümüzde Salar Türklerinin nüfusu 100.000'in üzerindedir ${ }^{3}$.

\footnotetext{
${ }^{1}$ Salar adı yerine Salar Türklerinin kendi yerleşim yerlerine (Hunhua/Salır) verdikleri addan dolayı Salır ifadesi de kullanılmaktadır. Ancak biz çalışmamızda daha yaygın olarak bilinen Salar adını tercih ettik. Bu ad ile ilgili E. R. Tenişev şunları söylemektedir: "Salar, Salır veya Sala (Çin. Salatszu) etnonimi, Oğuz etnik adlandırmaları arasına dâhil edilmektedir. Kaşgarlı Mahmut, bu etnonimin en eski şekli olan Salgur adını, Oğuz boylarından biri olarak verir. Daha sonra bu boy Salur veya Salor olarak adlandırıldı. Bu ad Dede Korkut'ta, Reşidüddin'de, Ebulgazi Bahadır Han'ın eserlerinde de bir Oğuz boyu olarak geçer. Salar adı ve Türkleri ile ilgili benzer bir analizi de V. V. Bartold yapar. Salgur, Salur, Salor, Salar, Salır gibi değişik kullanımları olan sözcük, sal- "koy-, bırak-" fiiline getirilen fiilden isim yapım ekinden oluşmaktadır. Nemeth'in görüşüne göre Salur sözcüğü "saldırıya hazır savaş̧̧ı" anlamına gelmektedir. Reşidüddin'de ise Salor teriminin yorumsal anlamda "kılıcı, silahı işleyen" manası bulunmaktadır." E. R. Tenişev, Stroy Salarskogo Yazıka - Salar Dilinin Yapısı, İzdatel'stvo NAUKA Glavnaya Redaktsiya Vostoçnoy Literaturı, Moskva 1976, s. 25.

${ }^{2}$ http://www.joshuaproject.net/people-profile.php?peo3=14658\&rog3=CH (25.02.2014)

${ }^{3}$ Salar Türklerinin nüfusu 1960'larda 40.000, 1973'te 40.000'den fazla, 1978'de 56.000, 1982'de yaklaşık 69.000, 1990'da yaklaşık 89.000, 1996'da 77.300, 2000'de 104.000 olarak hesaplanmıştır (Ersin Teres, İli Salır Türkçesinde Yapım Ekleri, Uluslararası Sosyal Araştırmalar Dergisi The Journal of International Social Research, Volume 6,
} 
Salar Türklerinin yaşadıkları bölgeler Çin, Dungan, Tibet ve Moğol halklarının yaşadıkları bölgeler ile çevrili durumda olduğundan, Salar Türkleri uzun yıllar bu halklar ile sıkı bir temas içerisinde olmuşlardır. Salar Türkleri birkaç dil bilseler de kendi aralarında ve aile içerisinde ana dillerini, resmi işlemlerde ise Çin edebi dilini kullanmaktadırlar. Ayrıca toplumdaki yerli Çinlilerle, Dunganlarla, Moğollarla ve Tibetlilerle de gereken şive ve ağızları kullanmaktadırlar ${ }^{4}$. Çoğu bölgede Salar Türklerinin \% 30’u ana dillerini aktif olarak kullanmaktadırlar. 60 yaşın üstü kadınlar ana dillerini iyi derecede bildiklerinden sözlü geleneğe de hâkim durumdadırlar. 35 yaşın üstünde olanlar akıcı konuşmaya yakın seviyede ana dillerini bilmektedirler. $\mathrm{Bu}$ grupta olanlar genellikle çok dillidirler ve sözlü kültürde aktif rol oynamazlar. Çocuklar ise yöredeki baskın dillerden biriyle yetişebilmektedir ${ }^{5}$.

Salar Türkçesi iki ana ağız bölgesinden oluşmaktadır: Salar Türklerinin yoğun olarak yaşadığı Hunhua, Hualong ve Gansu'da konuşulan Doğu (Çinghai) ağzi; İli ve Şincian’da konuşulan Batı (Şincian) ağzı. Salar Türkçesinin Batı ağzı Uygur ve Kazak Türkçelerinden etkilenmiştir ${ }^{6}$. Doğu ağzı ise daha çok Çince ve Tibetçeden etkilenmiştir. Doğu ağzı da kendi içerisinde Gaizi ve Mınta ağızlarına ayrılmaktadır . Her iki ana ağız grubunu da konuşanların sayısının gün geçtikçe azalması ve Salar Türkçesinin yazı dili olmaması, dilin geleceğini karamsarlaştırmaktadır ${ }^{8}$.

\section{2. Yalancı Eşdeğer}

Lehçeler arası aktarmalarda temel sorunlardan biri olan yalancı eşdeğerler ${ }^{9}$, iki lehçe ya da dil arasındaki aynı kökenden gelen sözcük ve yapıların sesçe tam ya da kısmen benzeşmesine veya benzeşmemesine rağmen anlamca örtüşmenin kısmen olması ya da hiç olmaması durumudur. Mustafa Uğurlu yalancı eşdeğerliği şöyle tanımlar:

Kaynak anlaşma birliğindeki bir kelimenin, ses ve yapı veya sadece ses bakımından aynı olan veya lehçeler arasındaki düzenli ses denklikleriyle aynı kaynaktan geldiği

Issue 24, Winter 2013, Issn:1307-9581, s. 333; E. R. Tenişev, age. s. 23; Arienne M. Dwyer, Salar Grammatical Sketch, www.mpi.nl/DOBES/projects/salar/salar.pdf. (25.02.2014), 1996 Qinghai Statistical Yearbook'a dayandırılarak verilmiştir).

${ }^{4}$ E. R. Tenişev, age., s. 23.

${ }^{5}$ Nezir Temur - Gülsün Mehmet, Salar Sözlü Edebiyatında İki Tür: Sagış ve Orıh Söz, Millî Folklor, 2010, Y11 22, Say1 86, s. 116; Arienne M. Dwyer, Salar Grammatical Sketch, www.mpi.nl/DOBES/projects/salar/salar.pdf. (25.02.2014)

${ }^{6}$ Arienne M. Dwyer, Salar Grammatical Sketch, www.mpi.nl/DOBES/projects/salar/salar.pdf. (25.02.2014)

${ }^{7}$ Ersin Teres, agm., s. 333.

${ }^{8}$ Arienne M. Dwyer, Salar Grammatical Sketch, www.mpi.nl/DOBES/projects/salar/salar.pdf. (25.02.2014)

${ }^{9}$ Mehmet Kara, Lehçeler Arası Aktarmalarda Temel Sorunlar, Turkish Studies International Periodical For the Languages, Literature and History of Turkish or Turkic, Volume 4/4 Summer 2009, s. 1062-1063. 
kolayca bilinen, yani benzer şeklinin, hedef lehçede bulunması; ancak bu iki kelimenin kavram alanlarının birbirine eşdeğer olmaması durumudur. ${ }^{10}$

Asker Resulov ise "yalancı eşdeğer” terimini şöyle açıklar:

Sözde eşdeğer olup gerçekte eşdeğer olmayan kelimelerdir. Çeviri biliminde 'yalancı eşdeğer' terimi ile kaynak dildeki bir kelimeyle amaç dildeki bir kelimenin köken, yazılış ve söylenişlerinin aynı, anlamlarının ayrı olması durumu ifade edilmektedir. $^{11}$

Türkçede yalancı eşdeğer terimi için "sahte karşılıklar, sözde denkteşler" ile tam yalancı eşdeğer kelimeler, sahte tanış, biçimdeş sözcükler, biçimsel eşteş sözcükler, yalancı eşteş, yanıltıcı eşteş, yalancı eşdeğerlik, yanlış arkadaş ve aldatıcı kelimeler" gibi karşılıklar da kullanılmaktadır ${ }^{13}$. Yalancı eşdeğer unsurlar için kullanılan terimlerden ve yapılan çalışmalardan anlaşıldığı üzere daha çok sözcük düzeyinde anlaşılan yalancı eşdeğerler, ek, ses ve sözcük grupları düzeylerinde de karşımıza çıkabilmektedir ${ }^{14}$.

Yalancı eşdeğerler, eşdeğer yapılara dayanmaktadır. Türkçe açısından bakıldığında Türk lehçelerinin ortak kaynaktan oluşması, Türklerin kendi aralarında göç ve karışmaların meydana gelmiş olması, aralarında kurdukları iktisadi, kültürel münasebetler ile dinî, siyasi yönlerden maruz kaldıkları yabancı etkiler Türk lehçeleri arasında benzeşen ve örtüşen unsurların oldukça çok olmasına vesile olmuştur ${ }^{15}$. Sözcük ya da yapılar arasındaki eşdeğerlilik şu hususlara göre belirlenir:

\begin{tabular}{|c|l|}
\hline \multirow{4}{*}{ SES } & a. Tam Benzeşenler \\
\cline { 2 - 2 } & b. Kismen Benzeşenler \\
\cline { 2 - 2 } & c. Benzeşmeyenler \\
\hline \multirow{2}{*}{ ANLAM } & a. Tam Örtüşenler \\
\cline { 2 - 2 } & b. Kismen Örtüşenler \\
\hline
\end{tabular}

\footnotetext{
${ }^{10}$ Mustafa Uğurlu, Türk Lehçeleri Arasında Benzer Kelimelerin Eşdeğerlik Durumu, Turkish Studies - International Periodical For The Languages, Literature and History of Turkish or Turkic, Volume 7/4, Fall 2012, s. 218.

${ }^{11}$ Asker Resulov, Akraba Diller ve "Yalancı Eşdeğerler" Sorunu, Türk Dili, Sayı 524, Ankara 1995, s. 916.

${ }^{12}$ Asker Resulov, agm., s. 916.

${ }^{13}$ Hanife Alkan, Lehçeler Arası Aktarmalarda Yalancı Eşdeğerler Sorunu (Türkiye Türkçesi - Özbek Türkçesi Yeni Uygur Türkçesi Fiil Örneği), Turkish Studies - International Periodical For The Languages, Literature and History of Turkish or Turkic, Volume 7/4, Fall 2012, s. 673.

${ }^{14}$ Ahmet Karadoğan, Türk Lehçeleri Arasında Yapı Eşdeğerliği ve Yalancı Eşdeğer Yapılar, V. Uluslararası Türk Dil Kurultayı Bildirileri I, 20-26 Eylül 2004, Ankara: TDK Yayınları, 1591-1604.

${ }^{15}$ Mustafa Uğurlu, agm., s. 217.
} 


\begin{tabular}{|l|l|}
\hline & c. Örtüşmeyenler \\
\hline \multirow{2}{*}{ KÖKEN } & a. Aynı Kökenden Gelenler \\
\cline { 2 - 2 } & b. Farklı Kökenden Gelenler \\
\hline
\end{tabular}

Eşdeğer unsurlar çeşitli sebeplerle yalancı eşdeğerlere dönüşebilmektedir. Türkçenin lehçeleri arasında yalancı eşdeğerlerin oluşma sebepleri şu şekilde sıralanabilir:

1. Türkçenin tarihî gelişimine bağlı olarak lehçe gruplarına ve bunların alt kollara ayr1lmas1;

2. Türk topluluklarının tarihî ve yakın dönemlerde olduğu gibi günümüzde de farklı siyasi birlikler içerisinde yer almaları;

3. Çok geniş bir coğrafyaya yayılmanın getirmiş olduğu sonuç olarak ortak bir kültürün paylaşı1mamasi;

4. Farklı dil, din ve kültürlerle ilişki kurulmuş olması;

5. Dilin kendi iç gelişmesi;

6. Ortak alıntı sözcüklerin farklı kavramlara karşılık kullanılması ve yazı dillerinin bu şekilde oluşturulması;

7. Ortak ana dildeki sözcüklerin her lehçede yazı diline girmemesinin sonucu olarak sözcüklerin konuşma dilinde kalması ve sözcüklerin temel anlamından farklı kullanılmaya başlanmas ${ }^{16}$.

Yalancı eşdeğerlerin odak noktasında "aynı kökenden gelme" bulunmaktadır. Dolayısıyla bu ifade ile daha çok aynı kökenden gelen sözcüklerdeki anlam farklılıkları (kısmen benzeşenler veya benzeşmeyenler) ve bunlara bağlı olarak ses durumları kastedilmektedir:

\begin{tabular}{|c|l|l|}
\hline \multirow{2}{*}{$\begin{array}{c}\text { KÖKEN } \\
\text { Aynı Kökenden Gelenler }\end{array}$} & SES $^{\mathbf{1 7}}$ & a. Tam Benzeşenler \\
\cline { 2 - 3 } & & b. Kısmen Benzeşenler \\
\cline { 2 - 3 } & & c. Benzeşmeyenler \\
\hline & & a. Kısmen Örtüşenler \\
\hline
\end{tabular}

\footnotetext{
${ }^{16}$ Asker Resulov, agm., s. 917-918.

${ }^{17}$ Ses bakımından benzeşmelerde hiçbir ses değişimi yoksa tam benzeşme; düzenli ses denklikleriyle aynı kaynaktan geldiği kolayca biliniyorsa kısmen benzeşme; aynı kaynaktan geldiği kolayca belli olmayacak kadar ses değişimi meydana gelmişse (daha çok Türkçenin uzak lehçelerinde) benzeşmeme durumu ortaya çıkmaktadır.
} 
ANLAM b. Örtüşmeyenler

Yukarıdaki tabloya göre yalancı eşdeğerler şu gruplara ayrılabilir:

1. Kökeni aynı, sesçe tam benzeşen ve anlamca kısmen örtüşen yalancı eşdeğerler;

2. Kökeni aynı, sesçe kısmen benzeşen ve anlamca kısmen örtüşen yalancı eşdeğerler;

3. Kökeni aynı, sesçe benzeşmeyen ve anlamca kısmen örtüşen yalancı eşdeğerler;

4. Kökeni aynı, sesçe tam benzeşen ve anlamca örtüşmeyen yalancı eşdeğerler;

5. Kökeni aynı, sesçe kısmen benzeşen ve anlamca örtüşmeyen yalancı eşdeğerler;

6. Kökeni aynı, sesçe benzeşmeyen ve anlamca örtüşmeyen yalancı eşdeğerler.

Asker Resulov ise yalancı eşdeğerleri üç grupta toplamıştır:

1. Eş adlı (homonim, sesteş) olanların yazılış ve söyleyiş̧leri rastlantısal olarak aynıdır; ancak kökenleri ve anlamları farklıdır.

2. Yazılış, söyleyiş ve köken bakımından aynı olup anlamları farklı olan yalancı eşdeğerler.

3. Yazılış, söyleyiş ve köken bakımından aynı olup anlamlarından biri veya birkaçı örtüşen, diğer anlamları ise örtüşmeyen yalancı eşdeğerler ${ }^{18}$.

Yalancı eşdeğerler sözcükler, ses özellikleri dikkate alınmadan köken-anlam açısından bakıldığında iki tür sınıflandırma yapılabilir:

1. Yarı Yalancı Eşdeğerler: Kökenleri aynı olan sözcüklerdeki bazı anlamların birbiriyle kısmen örtüştüğü yalancı eşdeğerlerdir. Bunlara "kısmî yalancı eşdeğer; göreceli yalancı eşdeğer" adı veren Asker Resulov, "kökenleri ve anlamlarından biri (genellikle 'düz anlamı') örtüşen, fakat anlam birimlerinden biri veya birkaçı değişik anlamlarda kullanılan kelimeler" biçiminde açıklama yapar ${ }^{19}$. Mustafa Uğurlu ise bu tür yalancı eşdeğerlere "kavram alanları tam örtüşmeyenler" veya "kısmî yalancı eşdeğer" adını vermektedir²0.

2. Tam Yalancı Eşdeğerler: Kökenleri aynı olan sözcüklerdeki anlamların birbiriyle hiç örtüşmediği yalancı eşdeğerlerdir. Bunlara "salt yalancı eşdeğerler", "kavram alanları hiç örtüşmeyenler, tam yalancı eşdeğer" ${ }^{\prime 22}$ de denilmektedir.

\footnotetext{
${ }^{18}$ Asker Resulov, agm., s. 917.

${ }^{19}$ Asker Resulov, agm., s. 921.

${ }^{20}$ Mustafa Uğurlu, agm., s. 218.

${ }^{21}$ Asker Resulov, agm., s. 921.
} 
Bu çalışmada Salar Türkçesi ile Türkiye Türkçesi arasındaki yalancı eşdeğer sözcükler, tespit edilerek önce sözcük türlerine göre daha sonra yarı ve tam yalancı eşdeğerler olarak siniflandırilacaktır.

\section{Salar Türkçesi Ve Türkiye Türkçesi Arasındaki Yalancı Eşdeğer Sözcükler ${ }^{23}$}

\section{1. İsimler}

\section{1. 1. Yarı Yalancı Eşdeğerler ${ }^{24}$}

İsim ve isim soylu sözcüklerin Salar Türkçesi ile Türkiye Türkçesi arasındaki yarı yalancı eşdeğerlikleri çok yaygın değildir:

ton "elbise" (SSY - 514) - don "giysi; vücudun belden aşağısına giyilen uzun veya kısa iç giysisi, külot” (TT)

tovah “yemek; kilden tabak" (SSY - 517) - tabak "yiyecek koymaya yarar, az derin ve yayvan kap" (TT)

tüs tiz tüz "ova, yazı" (SSY - 527) - düz "yatay durumda olan, eğik ve dik olmayan; kıvrımlı olmayan, doğru; yüzeyinde girinti çıkıntı olmayan engebesiz olan yer, düzlük, ova" (TT)

tüten $\sim$ dcüdcün $\sim \mathbf{d c}^{6}$ üten $\sim$ tütün $\sim$ dzüdcun $\sim$ dz'üdzün “duman” (SSY - 527) - tütün "patlıcangillerden, birleşiminde nikotin bulunan, otsu bir bitki; bu bitkinin kurutulup kıyılarak sigara biçiminde veya pipoyla içilen yaprağı; duman" (TT)

$\mathbf{u c ̧} \sim \mathbf{u c} \sim \overline{\mathbf{u}} \mathbf{c} \sim \mathbf{u d z} \sim \overline{\mathbf{u d z}}$ "avuç; el” (SSY - 531) - avuç "elin parmak uçlarıyla bilek arasındaki iç bölümü" (TT)

uçah "ocak; mutfak" (SSY - 531) - ocak "ateş yakmaya yarayan, pişirme, isıtma, ısınma vb. amaçlarla kullanılan yer" (TT)

un ůn "ses" (SSY - 534) - ün "herkesçe bilinme, tanınma durumu, san, şöhret, şan; ses" (TT) uy "ev; yılan yuvası" (SSY - 532) - ev "bir kimsenin veya ailenin içinde yaşadığ yer, konut, hane" (TT)

\footnotetext{
${ }^{22}$ Mustafa Uğurlu, agm., s. 218.

${ }^{23} \mathrm{Bu}$ çalışma E. R. Tenişev'in Salar Türkçesi ile ilgili olarak yazmış olduğu “Stroy Salarskogo Yazıka - Salar Dilinin Yapısı, İzdatel'stvo NAUKA Glavnaya Redaktsiya Vostoçnoy Literaturı, Moskva 1976" adlı eserde tespit edilmiş olan Salar Türkçesinin söz varlığına dayanmaktadır. Türkiye Türkçesi yazı dili ile karşılaştırma yapılırken Türk Dil Kurumu'nun internet sayfasında bulunan (http://www.tdk.gov.tr) Güncel Türkçe Sözlükten faydalanılmıştır.

${ }^{24}$ Yarı yalancı eşdeğer örneklerinde italik olarak verilen anlamlar, birbirleriyle örtüşen anlamları bildirmektedir.
} 


\section{1. 2. Tam Yalancı Eşdeğerler}

İsim ve isim soylu sözcüklerin Salar Türkçesi ile Türkiye Türkçesi arasındaki tam yalancı eşdeğerlikleri daha yaygındır:

aba "baba" (SSY - 279) - aba "abla, anne" (TT)

āğır "hasta" (SSY - 282) - ağrı "sanc1, s1Z1" (TT)

ana $\sim \overline{a n n a} \sim$ anna äna "k1z" (SSY - 288) - ana “anne" (TT)

anadz'uh anādz'uh "kız, küçük kı çocuğu" (SSY - 288) - anacık "annelere sevgiyle yaklaşıldığını belirten bir söz" (TT)

arga arha "sırt" (SSY - 292) - arka "bir şeyin temel tutulan yüzünün tam ters yanı, ön karşıtı" (TT)

arıhıs "kötü” (SSY - 294) - arsız “utanması, sıkılması olmayan, yılışık, yüzsüz” (TT)

aş āş "hamur" (SSY - 295) - aş “yemek" (TT)

aşāgı "kuzey” (SSY - 295) - aşağı "bir şeyin alt bölümü, zir, yukarı karşıtı" (TT)

bar $\sim$ bař $\sim$ par pař "zengin, varlıklı" (SSY - 300) - var "mevcut, evrende veya düşüncede yer alan, yok karşıtı” (TT)

dcüdcüh "erkeklik organı" (SSY - 305) - düdük "içinden hava veya buhar geçirildiğinde keskin ses çıkaran ve işaret vermek için kullanılan araç" (TT)

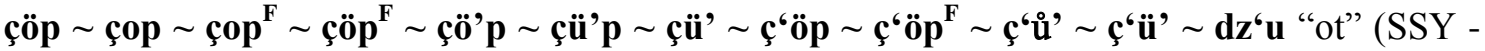
$314)$ - çöp "saman inceliğinde herhangi bir sap, dal veya tahta parçası" (TT)

gunah gūnah "suç, hatalı davranış" (SSY - 332) - günah "dinî bakımdan suç sayılan iş veya davranış, vebal" (TT)

irih ～ìruh irüh "kayıS1" (SSY - 339) - erik "gülgillerden, beyaz çiçekli bir ağaç (prunus domestica); bu ağacın kabuğu ince, çeşitli renklerde, mayhoş veya tatlı, eti sulu, tek ve sert çekirdekli yemişi” (TT)

yaman "çok" (SSY - 344) - yaman "güç, etki veya beceri bakımından alışılmışın üzerinde olan (kimse), alışılmadık, olağanın dışında" (TT)

yāman $\sim$ yaman $\sim$ yamen $\sim$ yämän $\sim$ yemen $\sim$ yēmen "bir şeye yetenekli" (SSY - 344) - yaman "güç, etki veya beceri bakımından alışılmışın üzerinde olan (kimse)" (TT)

yämän "kötü, zararlı" (SSY - 352) - yaman "kötü, korkulan (kimse)" (TT) 
yatuh yatı̧ "yastık" (SSY - 350) - yatık "dik olmayan, eğik, yatırılmış bir durumda olan" (TT)

yaz "ilkbahar" (SSY - 352) - yaz "ilkbaharla sonbahar arasındaki sıcak mevsim" (TT)

yüzluh “övme” (SSY - 369) - yüzlük“"sima, çehre, surat için olan” (TT)

yırtıh $\sim$ yertah $\sim$ yirtah $\sim$ yiřtıh $\sim$ yirtıh $\sim$ ritah $\sim$ rituh "vahşi, yırtıcı" (SSY - 370) - yırtık “yırtılmış olan, eskimiş, parçalanmış" (TT)

kēce $\sim$ gece $\sim$ gedze $\sim$ keçi $\sim$ kēçı $\sim$ kece "akşam" (SSY - 378) - gece "genellikle saat 22.00'den itibaren gün ağarıncaya kadar geçen süre, tün, şeb" (TT)

keş "akşam" (SSY - 380) - gece "genellikle saat 22.00'den itibaren gün ağarıncaya kadar geçen süre, tün, şeb" (TT)

konah "misafir, konuk" (SSY - 388) - konak "büyük ve gösterişli ev" (TT)

māsım masım "üç yaşından küçük çocuklar" (SSY - 408) - masum "suçsuz, günahsız; temiz; küçük çocuk" (TT)

menze meyes "beyin" (SSY - 409) - beniz “yüz; yüz rengi” (TT)

meyz1 menzi "alın" (SSY - 410) - beniz "yüz; yüz rengi” (TT)

neşler? "nasılsın?” (SSY - 418) - ne işler? "işin adını öğrenmeye yönelik soru” (TT)

ompirinci "kasım" (SSY - 425) - on birinci “on bir sayısının sırasını anlatır" (TT)

on işkinci "aralık" (SSY - 425) - on ikinci “on iki sayısının sırasını anlatır” (TT)

onınci “ekim" (SSY - 426) - onuncu "on sayısının sirasını anlatı"” (TT)

ơrmeh "çuha, tüysüz kumaş" (SSY - 426) - örmek "iplik, yün, tel, saz vb.ni birbirine dolayarak veya geçirerek işlemek veya tezgâhta dokumak" (TT)

o'ta "sine" (SSY - 429) - orta "bir şeyin kenarlarından merkeze doğru yaklaşık olarak aynı uzaklıkta olan yer" (TT)

ozengu "merdiven" (SSY - 431) - üzengi "eyerin iki yanında as1lı bulunan ve hayvana binildiğinde ayakların basılmasına yarayan, altı düz demir halka” (TT)

ozeh ōzeh özeh "temel, ana” (SSY - 431) - özek “merkez" (TT)

paba "dede; amca" (434) - baba "çocuğu olan erkek, peder" (TT)

pāhımci "doktor, hekim” (SSY - 440) - bakımcı "bakım işini yapan kimse" (TT)

pōğınah pōgınıh "ejderha" (SSY - 451) - boğanak "sağanak, bora" (TT) 
poh poğ $\sim$ poh puh "çöp; tortu” (SSY - 454, SSY - 457) - bok "dışk1; güç durum; hor görülen, tiksinilen" (TT)

kaş "yan, kenar; yakın” (SSY - 462) - kaş “eyerin ön ve arkasındaki çıkıntılı bölüm; sarp kayalık, uçurum; bağ ve bahçelerde toprak yığarak yapılan sınır, set” (TT)

kol "el” (SSY - 464) - kol "insan vücudunda omuz başından parmak uçlarına kadar uzanan bölüm” (TT)

kol "küçük ırmak; kanal" (SSY - 464) - kol "insan vücudunda omuz başından parmak uçlarına kadar uzanan bölüm” (TT)

sāçah "bitki kökü" (SSY - 470) - saçak "bazı giyim eşyalarında veya döşemeliklerde kumaş kenarlarına dikilen süslü iplikten püskül” (TT)

sorgu "soru" (SSY - 485) - sorgu "sorma işi; sanığın araştırma konusu olayla ilgili olarak yargıç karşısındaki beyanı" (TT)

suçıh sudc'ạ sudc'dc'uh suççıh sutdz'ah suçıhdzuh "varil, su için küçük fiçı" (SSY 487) - su+clk “su sözcügüne küçültme ekinin getirilmiş hâli” (TT)

sıbsınci “ağustos” (SSY - 493) - sekizinci "sekiz rakamının sırasını anlatır” (TT)

tal tāl "ağaç" (SSY - 499) - dal "ağacın gövdesinden ayrılan kollardan her biri” (TT)

tam tām "duvar" (SSY - 500) - dam "yapıları dış etkilerden korumak amacıyla üzerlerine yapılan çoğu kiremit kaplı bölüm; üzeri toprak kaplı ev, küçük ev, köy evi” (TT)

tēşuh $\sim$ teşüh $\sim$ tēşüh $\sim$ tīşuh $\sim$ tişüh $\sim$ tişuh $\sim$ tişüh "uçurum; delik" (SSY -509 ) - deşik "deşilmiş olan; deş-: oymak, delmek, yara açmak, içini açmak, karıştırmak, kazmak" (TT)

tombıh "aptal" (SSY - 513) - tombik "küçük ve şişman çocuk" (TT)

tohssınci "eylül” (SSY - 518) - dokuzuncu "dokuz rakamının sırasını anlatır" (TT)

tö’tinci “nisan” (SSY - 521) - dördüncü “dört rakamının sırasını anlatır” (TT)

tuman "sis" (SSY - 523) - duman "bir maddenin yanması ile çıkan ve içinde katı zerrelerle buğu bulunan değişik renklerde gaz; havalanan tozların veya sisin oluşturduğu bulanıklık" (TT) uhuçi “öğrenci” (SSY - 536) - okuyucu "sürekli olarak gazete, dergi vb. okuyan, okur” (TT) üçince “mart” (SSY - 538) - üçüncü “üç rakamının sırasını anlatır” (TT) halgeş “övgü, takdir, tasvip" (SSY - 555) - alkış "bir şeyin beğenildiğini, onaylandığını anlatmak için el çırpma, alkışlama” (TT) 
hap "kıldan yapılmış çuval” (SSY - 555) - kap "içi gaz, sıv1 veya katı herhangi bir maddeyi alabilen oyuk nesne" (TT)

ISSI ISı "sıcak" (SSY - 560) - ISı "bir cismin uzamasına, genleşmesine, buharlaşmasına, erimesine, sıcaklığının artmasına yol açan fiziksel enerji; fiziksel bir olaya dayalı, belirli bir ölçü üzerine kurulmuş olan sıcaklık ve soğukluk derecesi” (TT)

\section{2. Fiiller}

\section{2. 1. Yarı Yalancı Eșdeğerler}

Fiillerin Salar Türkçesi ile Türkiye Türkçesi arasındaki yarı yalancı eşdeğerlikleri çok yaygın değildir:

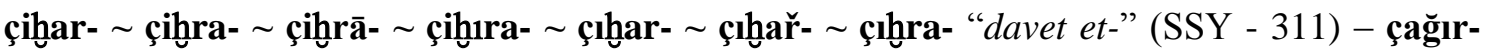
"birinin gelmesini kendisine yüksek sesle söyle-, seslen-; herhangi birinin bir yere gelmesini iste-, davet et-"; çı̆̆ır- "çağır-, seslen-" (TT)

ohşi- ohşşa- "benze-, andır-, hatırlat-" (SSY - 430) - okşa- "sevgi, şefkat belirtisi olarak elini bir şeyin üzerinde yavaş yavaş gezdir-, hafifçe vur-; hafifçe dokun-; benze-, andır-, hatırlat-" (TT)

oza'- oza't- uza't- uza'- "gönder-" (SSY - 431) - uzat- "uzamasına sebep ol-, uzamasin1 sağla-; başı, kolları veya bacakları bir yere yönelt-; bir şeyi vermek için birine yönelt-; ger-; ver, gönder-" (TT)

sal- "koy-, brrak-" (SSY - 471) - sal- "bağımlılı̆̆ına, tutukluluğuna veya bask1 altındaki durumuna son vererek serbest kıl-, bırak-, koyuver-; yolla-, gönder-; koy-, kat-" (TT)

tat- $\sim$ tā- $\sim$ ta'- tā'- ta't- tāt- "çek-, ger-" (SSY - 505) - tart- "bir şeyin birim cinsten ağırlığını bul-; bir şeyi avuç içinde sallayarak ağırlığını kestirmeye çalış-; binek hayvanlarının dizginlerini çek-" (TT)

\section{2. 2. Tam Yalancı Eşdeğerler}

Fiillerin Salar Türkçesi ile Türkiye Türkçesi arasındaki tam yalancı eşdeğerlikleri daha yaygindır:

açıblan- "sinirlen-" (SSY - 280) - acılan- "tadı acı ol-, acılaş-; acılı durumda ol-, üzüntüye kap1l-, üzül-” (TT)

ağrı- ağır- agır- agırl- "hastalan-" (SSY - 281) - ağrl- "vücudun bir yeri ağrılı durumda ol-" (TT) 
aliş- āliş- "değiş̧tir-" (SSY - 287) - alış- "bir işi tekrarlayarak kolaylıkla yapabil-; yadırgamaz duruma gel-; uyar duruma gel-, intibak et-; sürekli ister ol-, bağımlılık kazan-; bağlan-, 1sın-" (TT)

ạnaş- "sor-; bildir-" (SSY - 290) - anlaş- "düşünce, duygu, amaç bakımından birleş-" (TT)

çeh- "tartı̧̧-” (SSY - 309) - çek- "bir şeyi tutup kendine veya başka bir yöne doğru yürüt-" (TT) ç'at- "k1lıçla kes-" (SSY - 317) - çat- "odun, değnek, k1lıç, tüfek vb. uzun şeylerden birkaç tanesini, tepelerinden birbirine çaprazlama dayayarak durdur-" (TT)

eri- ēri- "takip et-, izle-" (SSY - 326) - er- "eriş-; kavuş-; insan veya bitki büyüyüp geliş-, yetiş-; ürün olgunlaş-; kendini Tanrı yoluna vermiş kimse insanüstü kutsal bir aşamaya erişs"” (TT)

işte- içte- işti- işdci- iştä- "ara-" (SSY - 340) - izle- "birinin veya bir şeyin arkasından git-, takip et-; zaman, süre, sıra $v b$. bakımından gel-, arkasından gel-, arkasında ol-” (TT)

iş- iç- îş- "yemek ye-" (SSY - 340) - iç- "bir sıvıyı ağza alıp yut-" (TT)

yan- "geri dön-" (SSY - 345) - yan- "birleşiminde karbon bulunan maddeler, 1s1 ve 1ş1k yayarak kül durumuna geçip yok ol-; ateş durumuna geç-, tutuş-; 1s1, 1ş1k veren bir konuma geç-” (TT)

yohlan- yohlan- "fakirleş-" (SSY - 363) - yokla-n- "yoklama işine konu ol-; yokla-: dokunarak incele-; bak-, gözden geçir-, kontrol et-" (TT)

kaç- kāş- kaş- "gizle-" (SSY - 373) - kaç- "hızla koşup bir yere saklan-; kimseye bildirmeden bulunduğu yerden ayrıl-, firar et-" (TT)

kohla- "gagala-" (SSY - 391) - kak-la- "kak-: it-, vur-; kakma yap-; vurarak dar bir yere sok-" (TT)

kut- kü’t- "sırtında taş1-" (SSY - 397) - göt-ür- "taşı-, ulaştır- veya koy-; bir kimseyi bir yere kadar yanında yürüt-" (TT)

oynaş- "birbiriyle oyna-" (SSY - 424) - oynaş- "birbiriyle oyna-; karş11ıklı seviş-, sevgi gösterisinde bulun-, cilveleş-” (TT)

ona- on1- ōn1- "anlaş-, razı ol-" (SSY - 425) - ona- "bir işi doğru ve uygun bul-, tasvip et-" (TT)

oyar- oyur- oyır- unar- uyor- "sök-, kopar-" (SSY - 426) - onar- "bozulmuş, eskimiş olan bir şeyi düzeltip işler veya kullanılır duruma sok-, işe yarar duruma getir-, tamir et-" (TT) ömehlen- "eğil-, alçal-" (SSY - 432) - emekle-n- "emekle-: dizler ve eller üzerinde yürü-" (TT) 
öt- òt- ote- ö'- ůt- "geç-” (SSY - 433) - öt- "kuş veya böceklerde değiş̧ik tonda ses çıkar-" (TT)

par- bar- pā- pař- va- vā- var- vār- vař- vāř- "git-" (SSY - 437) - var"erişilmek istenen yere ayak bas-, ulaş-; belli bir duruma veya düzeye gel-" (TT)

pogun- "kendini as-" (SSY - 451) - boğ-ul- "boğma işine konu ol-; havasızlıktan öl-; bunal-" (TT)

kaldır- "durdur-" (SSY - 460) - kaldır- "bulunduğu yerden al-; yukarı doğru hareket ettir-; yükselt-" (TT)

sahla- sahlā- sihlā- "koru-, bekle-" (SSY - 476) - sakla- "elinde bulundur-, tut-; kaybolmamas1, görünmemesi için gizli bir yere koy-; koru-, esirge-" (TT)

tana- "seç-, ayıkla-" (SSY - 500) - tanı- "daha önce görülen, bilinen bir kimse veya şeyle karşılaşıldığında bunun kim veya ne olduğunu hatırlamak; daha önce görmüş olmak, ilişkisi bulunmak, bilmek" (TT)

tap- $\sim$ ta $^{\mathrm{p}} \mathrm{f}-\sim$ ta'p- $\sim$ ta'- "bul-" (SSY - 502) - tap- "ilah olarak tanınan varlığa karş1 inancını ve bağl11ı̆̆ını belirli kurallar çerçevesinde göster-; tutku ile sev-, bağlan-; birine çok değer ver-" (TT)

tah- tah- tāh- "as-" (SSY - 506) - tak- "bir şeyi başka bir yere uygun bir biçimde tuttur-, iliştir-, geçir-" (TT)

teş- tiş- “yak-" (SSY - 509) - deş- "oy-, del-, yara aç-, içini aç-, karıştır-, kaz-" (TT)

tōla- tōlā- "kaz-, eş-" (SSY - 513) - dola- "iplik, şerit, tel $v b$. nesneleri bir şeyin üzerine döndürerek sar-; sar-, kavuştur-" (TT)

ūs1l- usal- uzil- "geniş̧le-, aç1l-" (SSY - 535) - uza-l- "uza-: uzun duruma gel-, boyu büyü-; çok zaman tut-, uzun sür-” (TT)

h`ār- hor- ho'par- hovar- hovir- huvar- "kaldır-" (SSY - 547) - kopar- "kopmasını sağla-, kopmasına yol aç-; daldan, ağaçtan alıp topla-; birden ve güçlü bir biçimde başla-, başlat-; zor kullanarak al-" (TT)

\section{Sonuç}

Oğuz grubuna bağlı iki lehçe olan Salar Türkçesi ile Türkiye Türkçesi arasındaki yalancı eşdeğerler, iki lehçeyi konuşanların anlaşmasına engel olacak kadar yaygın değildir. Bu nedenle iki lehçe arasındaki aktarmalarda yalancı eşdeğerlerden daha çok, alfabe ve transkripsiyon engel oluşturmaktadır. 
Tespitlerimize göre sözcük türü olarak isim ve fiiller yalancı eşdeğer durumunda olabilmektedir. Yalancı eşdeğerler ağırlıklı olarak tam yalancı eşdeğer özelliği göstermektedirler. Ses açısından ise kısmen benzeşme (arga arha "sırt”, meநzz1 "beniz”, par"var-" vb.) çok yaygındır. Tam benzeşme (aş "yemek", kaldır- "durdur-", yan- "geri dön-" vb.), Salar Türkçesinin Çin ve Tibet dillerinin yoğun etkisinde kalmış olmasından, Türkçenin tarihî gelişimine bağlı olarak iki lehçede ses değişimlerinin oluşmasından ve bunları göz önünde bulunduran Tenişev'in eserinde detaylı bir transkripsiyon alfabesi kullanmasından ötürü yaygın olarak tespit edilememiştir. Ses olarak benzeşmenin olmadığ 1 ( $d z^{\prime} u$ "ot” $v b$.) yalancı eşdeğerler, Türkçe sözcüklerin Çince ve Tibetçe telaffuz ediliş şekillerinin metne aktarılmasından kaynaklanmakta ve bunlara nadiren rastlanmaktadır.

Yalanc1 eşdeğer olarak verdiğimiz örneklerin birçoğunun anlamı Türkiye Türkçesi ağızlarında da yaşamaktadır:

uçah “ocak; mutfak" (SSY - 531) - ocak "ateş yakmaya yarayan, pişirme, ısıtma, ısınma vb. amaçlarla kullanılan yer" (TT) - ocaklık "mutfak" (TTA)

tüten $\sim$ dcüdcün $\sim$ dc'üten $\sim$ tütün $\sim$ dzüdcun $\sim$ dz'üdzün “duman” (SSY - 527) - tütün "patlıcangillerden, birleşiminde nikotin bulunan, otsu bir bitki; bu bitkinin kurutulup kıyılarak sigara biçiminde veya pipoyla içilen yaprağı; duman" (TT) - tütün “duman” (TTA)

tap- $\sim \operatorname{ta}^{\mathrm{p}} \mathrm{f}-\sim$ ta'p- $\sim$ ta'- "bul-" (SSY - 502) - tap- "ilah olarak tanınan varlığa karşı inancını ve bağl1lı̆̆ını belirli kurallar çerçevesinde göster-; tutku ile sev-, bağlan-; birine çok değer ver-" (TT) - tapmak "bul-" (TTA)

Salar Türkçesindeki yalancı eşdeğerler, diğer lehçelerdeki yalancı eşdeğerlerle ortaklık göstermektedir: ün "ses” (Kırg.), ton “elbise” (Kırg., Nog.), tap- "bul-” (Nog., Tat., Kirg., Türk.), sal- "koy-, bırak-" (Kırg., Türk.) vb.

Tespit ettiğimiz yalancı eşdeğerlerin, Türkiye Türkçesinden oldukça uzak bir coğrafyada ve sınırlı seviyede konuşulmakta olan Salar Türkçesi ile ilgili yapılacak aktarmalarda ve çalışmalarda yararlı olacağı kanısındayız. Bir Oğuz grubu olan ve gün geçtikçe konuşma oranı azalarak baskın dil ve ağızların etkisi altında yaşama mücadelesi veren Salar Türkçesi üzerine yapılacak her çalışma Türkçe için büyük önem arz etmektedir.

\section{Kisaltmalar}

SSY : Stroy Salarskogo Yazıka - Salar Dilinin Yapısı

TT : Türkiye Türkçesi

TTA : Türkiye Türkçesi Ağızları

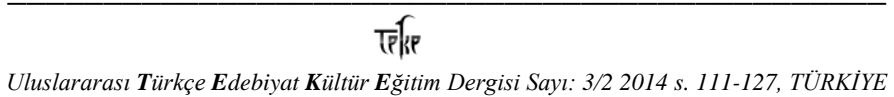

International Journal of Turkish Literature Culture Education Volume 3/2 2014 p. 111-127, TURKEY 
Kırg. Kırgız Türkçesi

Nog. : Nogay Türkçesi

Tat. : Tatar Türkçesi

Türk. : Türkmen Türkçesi

\section{Transkripsiyon Alfabesi}

$\overline{\mathbf{a}} \quad$ : Uzun “a” ünlüsüdür. SSY'de aynı işaretle gösterilmektedir.

ä $\quad$ : “a, e” arası açık "e” ünlüsünü karşılar. SSY'de aynı işaretle gösterilmektedir.

e $\quad$ : Uzun “e” ünlüsüdür. SSY'de aynı işaretle gösterilmektedir.

$\overline{\mathbf{i}} \quad$ : Uzun “i” ünlüsüdür. SSY'de aynı işaretle gösterilmektedir.

o : : Uzun “o” ünlüsüdür. SSY'de aynı işaretle gösterilmektedir.

$\overline{\mathbf{u}} \quad$ : Uzun “u” ünlüsüdür. SSY'de aynı işaretle gösterilmektedir.

ů : Ön sıradan olan ve palatallaşmış ünsüzlerle birlikte kullanılan “u” ünlüsüdür. SSY'de aynı işaretle gösterilmektedir.

dc : Yumuşak tonsuz (slabaya gluhaya), üflemesiz (nepridıhatel'nıy), ön dil (peredneyazıçnıy (dorsal'naya)), ıslıklı (svistyaşiy), yarı kapantılı (affrikat). Çinceye ait bir sestir. SSY'de “c” ile gösterilmektedir.

dc' : Sert tonsuz (sil'naya gluhaya), üflemeli (pridıhatel'nıy), ön dil (peredneyazıçnıy (dorsal'naya)), 1slıklı (svistyaşiy), yarı kapantılı (affrikat). Çinceye ait bir sestir. SSY'de "cc" ile gösterilmektedir.

dz : Yumuşak tonsuz (slabaya gluhaya), üflemesiz (nepridıhatel'nıy), ön dil (peredneyazıçnıy (dorsal'naya)), hışırtılı (şipyaşaya), yarı kapantılı (affrikat). Çinceye ait bir sestir. SSY'de "3" ile gösterilmektedir.

$\mathbf{d z}^{\mathbf{6}} \quad$ : Sert tonsuz (sil'naya gluhaya), üflemeli (pridıhatel'nıy), ön dil (peredneyazıçnıy (dorsal'naya)), hışırtılı (şipyaşaya), yarı kapantılı (affrikat). Çinceye ait bir sestir. SSY'de " 3 “ " ile gösterilmektedir.

h $\quad$ : Yumuşak tonsuz (slabaya gluhaya), küçük dil ünsüzü, gırtlak (uvulyarnıy), sızıcı (şelevaya). SSY'de “x” ile gösterilmektedir. 
$\mathbf{h}^{\circ} \quad$ : Dudak ünlülerinden önce kullanılan dudaksıl sızıc1 "hु" ünsüzüdür. SSY'de “x”" ile gösterilmektedir.

y $\quad$ : Sürekli damak sesi olan "n” ünsüzüdür. SSY'de aynı işaretle gösterilmektedir.

r $\quad$ : Ön dil (peredneyazıçnıy (dorsal'naya)), akıcı (sonant), titrek ya da çarpmalı (drojaşiy).

SSY'de aynı işaretle gösterilmektedir.

$\mathbf{p}^{\mathbf{F}} \quad$ : “p - f” arası sestir. SSY'de aynı işaretle gösterilmektedir.

${ }^{\mathrm{p}} \mathbf{f} \quad$ : “f $-\mathrm{p}$ " arası sestir. SSY'de aynı işaretle gösterilmektedir.

، : : Seslerin önce ya da sonra nefesle telaffuz edildiğini gösteren işarettir. SSY'de aynı işaretle gösterilmektedir.

\section{Kaynaklar}

ADIGÜZEL, S. (2012). Azerbaycan Türkçesi ve Türkiye Türkçesi Arasında Aktarma Üzerine Bazı Problemler. Atatürk Üniversitesi Türkiyat Araştırmaları Enstitüsü Dergisi (TAED), 47, Erzurum, 51-56.

AKBABA, D. E. (2007). Nogay Türkçesi ve Türkiye Türkçesi Arasındaki Yalancı Eşdeğerler. Bilig, S. 42, 151-176.

AKSAN, D. (2007). Her Yönüyle Dil (Ana Çizgileriyle Dilbilim). Ankara: Türk Dil Kurumu Yayınları.

ALKAN, H. (2012). Lehçeler Arası Aktarmalarda Yalancı Eşdeğerler Sorunu (Türkiye Türkçesi - Özbek Türkçesi - Yeni Uygur Türkçesi Fiil Örneği). Turkish Studies - International Periodical For The Languages, Literature and History of Turkish or Turkic. Volume 7/4, Fall 2012, 671-688.

ALKAYIŞ, M. F. (2009). Çağdaş Türk Şiveleri Arasında aktarma Meseleleri (Türkiye TürkçesiYeni Uygur Türkçesi Örneği). Turkish Studies International Periodical For the Languages, Literature and History of Turkish or Turkic, 4/3 (Ilkbahar/2009), 60-70.

ARNAZAROV, S. (2008). Türkmen ve Türkiye Türkçesinde Bazı Ortak Fiillerde Yalancı Eşdeğerlik. Gazi Türkiyat, Güz 2008, 3, 31- 49.

BEŞEN DELİCE, T. (2013). Türkmen Türkçesinde Yalancı Eşdeğerler. Uluslararası Türkçe Edebiyat Kültür Eğitim Dergisi (TEKE), 2/4 2013, 131-146.

DURDUYEV, M. (1998). Çin Türkmenleri. (Çev. Saadettin Gömeç). Tarih Araştırmaları Dergisi, Cilt 19, Sayı 30, Ankara, 319-364.

ERSOY, F. (2007). Çuvaş Türkçesi ve Türkiye Türkçesinde Yalancı Eşdeğerler. Türkbilig, 2007/14, 60-68.

İLKER, A. (1999). Lehçeden Lehçeye Aktarma Üzerine Bazı Düşünceler. 3. Uluslararası Türk Dil Kurultayı 1996, Ankara: TDK Yayınları, 553-559.

KARA, M. (2003). Lehçeler Arası Aktarmalarda Temel Sorunlar. Turkish Studies International Periodical For the Languages, Literature and History of Turkish or Turkic, Volume 4/4 Summer 2009, 1056-1082. 
KARADOĞAN, A. (2004). Türk Lehçeleri Arasında Yapı Eşdeğerliği ve Yalancı Eşdeğer Yapılar. V. Uluslararası Türk Dil Kurultayı Bildirileri I, 20-26 Eylül 2004, Ankara: TDK Yayınlar1, 1591-1604.

KİIŞÇİĞLLU, F. (2006). Türkmen Türkçesinden Türkiye Türkçesine Yapılan Aktarmalarda Karşılaşılan Bazı Problemler. Selçuk Üniversitesi Türkiyat Araştırmaları Dergisi, S. 20, 21-35.

ÖLMEZ, M. (2012). Oğuzların En Doğudaki Kolu: Salırlar ve Dilleri. Türk Dili, Aralık 2012, Cilt: CII, Sayı 732, 38-43.

RESULOV, A. (1995). Akraba Diller ve Yalancı Eşdeğerler Sorunu. Türk Dili, Sayı 524, 916924.

TEMUR, N. - MEHMET, G. (2010). Salar Sözlü Edebiyatında İki Tür: Sagış ve Orıh Söz. Millî Folklor, Y11 22, Say1 86, 115-126.

TENiŞEV, E. R. (1976). Stroy Salarskogo Yazıka - Salar Dilinin Yapısı. Moskva: İzdatel'stvo "NAUKA" Glavnaya Redaktsiya Vostoçnoy Literaturı.

TERES, E. (2011). İli Salır Türkçesi ve Türkmen Türkçesinde İsim Çekimi. Sosyal Araştırmalar Dergisi, C 4, 18, Ordu, 142-150.

TERES, E. (2012). Salır Türklerinin Kaynakları ve Salır Türkçesi Üzerine Araştırmalar. Türkiyat Mecmuasl, C 22 / Güz 2012, 103-126.

TERES, E. (2013). İli Salır Türkçesinde Yapım Ekleri. Uluslararası Sosyal Araştırmalar Dergisi The Journal of International Social Research, Volume 6, Issue 24, Winter 2013, 332-347.

UĞURLU, M. (2012). Türk Lehçeleri Arasında Benzer Kelimelerin Eşdeğerlik Durumu. Turkish Studies - International Periodical For The Languages, Literature and History of Turkish or Turkic, Volume 7/4, Fall 2012, 215-222.

\section{İnternet Kaynakları}

Dwyer, Arienne M. Salar Grammatical Sketch, www.mpi.nl/DOBES/projects/salar/salar.pdf. (25.02.2014)

http://www.joshuaproject.net/people-profile.php?peo3=14658\&rog3=CH (25.02.2014)

http://tdk.org.tr 